\title{
Flâneur, blasé, zappeur: variações sobre o tema do indivíduo
}

\author{
Marco Toledo de Assis Bastos ${ }^{1}$
}

RESUMO: O presente artigo vasculha, nos tipos da modernidade, elementos que contribuam para a descrição dos personagens contemporâneos. Da reinvenção da cidade pelo flâneur, que desliza pelo tecido urbano, aos elementos impessoais identificados por Simmel no comportamento blasé, abundam imagens de uma civilização dinamizada pela vida privada. Do flanador ao blasé, e do blasé ao zapeador, há uma linha contígua na individuação moderna, infelizmente de difícil apreensão. Isso porque quão maior a invisibilidade desses indivíduos, maiores as possibilidades de leituras sociais. $O$ presente artigo procura assim problematizar o conceito de indivíduo, em oposição a categorias universais como sujeito ou cultura e rumo às menores células sociais.

PALAVRAS-CHAVE: Flanador; Blasé; Zapeador

ABSTRACT: The following article searches thoroughly the characters modernity has brought to us, seeking out contributions for portraying contemporary personae. From the reinvention of the city by the French flâneur and its particular way of moving around up to the impersonal elements Simmel found out on the blasé behavior, there are several images of a civilization dynamized by private life. From the flâneur to the blasé, and from the blasé to the zappeur, there is a straight line in what regards modern individuation, even though out of plain sight. This is because the less visible these characters are, the better are the chances for social analysis. The following article is thus an attempt to work out the concept of individual as a minor social cluster, in opposition to wide-ranging concepts such as subject or even culture.

KEY WORDS: Flâneur; Blasé; Zappeur

RESUMEN: El presente artículo investiga en los tipos de la modernidad elementos para describir los personajes de la contemporaneidad. Desde el recrear de la ciudad por el flâneur, que desliza por el paisaje urbano, hasta los elementos impersonales que Simmel identifica en la conducta blasé, hay muchas imágenes de una civilización dinamizada por la vida privada. Desde el flâneur hasta el blasé, y desde el blasé hasta el zappeur, hay contigüidad en la individuación moderna aunque de dificultosa aprehensión, puesto que cuanto menos visibles son los individuos, más grandes las posibilidades de lecturas sociales. El presente artículo intenta así interrogarse sobre el concepto de individuo, en oposición a categorías universales como sujeto o cultura y a camino de las más pequeñas células sociales.

PALABRAS CLAVES: Flaneur; Blasé; Zappeur

RÉSUMÉ: Cet article cherche à fond dans les caractères de la modernité les éléments qui contribuent pour la description des personnages contemporains. De la réinvention de la cité pour le flâneur, qui se glisse à travers du tissu urbain aux éléments impersonnels identifiés pour Simmel dans le comportement blasé, abondent des images d'une civilisation dynamisée par la vie privée. Du flâneur au blasé, et du blasé au zappeur, il y a une ligne continuelle dans la individuation moderne, malheureusement de difficile appréciation. C'est parce que les moins visibles sont ces individues, les mieux sont les possibilités de faire des lectures sociales. Cet article donc éssai définir le concept de l'individu, à l'opposé des catégories universelles comme sujet et culture, et en direction de les plus petites cellules sociales.

MOTS-CLÉ: Flâneur; Blasé; Zappeur 
O modo como pessoas individuais definem individualmente seus problemas individuais e os enfrentam com habilidades e recursos individuais é a única questão pública remanescente.

Zygmunt Bauman $^{2}$

\section{O INDIVÍDUO}

A maldição da modernidade é sua herança teleológica, cujo tratamento analítico circunscreve os problemas em arcabouços totalizantes. Como seu ideário fundador é o universalismo racionalista, fora imperioso às teorias sociais de então se proporem a si mesmas como ciência. Importa menos os objetos e indivíduos, qualquer especificidade. É preciso encontrar o universalismo que caracteriza uma cultura, uma sociedade. Cultura seria então toda produção social, material e imaterial, uma estrutura total ou paradigma invisível que explicaria todo o corpo social, toda a mega-máquina de produção simbólica que é a fabricação de uma sociedade. As relações e mediações entre indivíduo e espaço ficam mormente emagrecidas em uma abordagem que foca o todo.

Zygmunt Bauman comenta o problema, parafraseando a inscrição do Portal do Inferno de Dante Alighieri: abandonai toda esperança de totalidade, tanto futura como passada, vós que entrais no mundo da modernidade fluida. Chegou o tempo de anunciar, como o fez recentemente Alain Touraine, o fim da definição do ser humano como um ser social. Em seu lugar, o princípio da combinação da definição estratégica da ação social que não é orientada por normas sociais; pode ser encontrado dentro do indivíduo, e não mais em instituições sociais ou em princípios universais ${ }^{3}$. Bauman entende a modernidade dentro de uma tipologia termodinâmica, que foi sucintamente explicada nessa entrevista:

Tudo é temporário. É por isso que sugeri a metáfora da "liquidez" para caracterizar o estado da sociedade moderna, que, como os líquidos, se caracteriza por uma incapacidade de manter a forma. Nossas instituições, quadros de referência, estilos de vida, crenças e conviç̧ões mudam antes que tenham tempo de se solidificar em costumes, hábitos e verdades 'autoevidentes'. É verdade que a vida moderna foi desde o início "desenraizadora” e "derretia os sólidos e profanava os sagrados", como os jovens Marx e Engels notaram. Mas, enquanto no passado isso se fazia para ser novamente "reenraizado", agora as coisas todas - empregos, relacionamentos, etc. - tendem a permanecer em fluxo, voláteis, desreguladas, flexíveis. ${ }^{4}$ 
A retomada da categoria do indivíduo, da menor unidade social, serve a uma radiografia social que, nos termos de Simmel, pode penetrar no significado íntimo da vida moderna e de seus produtos, penetrar na alma do corpo cultural, buscando resolver a equação: que estruturas se dispõem entre os conteúdos individual e superindividual da vida ${ }^{5} \mathrm{O}$ próprio mapear das personalidades individuais junto a forças externas é, no sentido referido por Bauman, o relacionar de cada estratégia de vida particular às formações sociais, à suas racionalidades específicas ${ }^{6}$.

O problema do conceito é sua herança do liberalismo econômico, para quem indivíduo significa exclusivamente consumidor. Também a ciência política entendia a categoria como ferramenta ideológica do conservadorismo político, na medida em que se recusava a trabalhar qualquer instância cultural, social ou política, perfazendo toda análise por meio de condicionantes e determinantes econômicos. Mas nem consumidor, nem idiossincrasias individuais são instâncias anódinas.

De todo modo, a ciência política e o liberalismo econômico não esgotaram a idéia. O sociólogo francês Gabriel Tarde ${ }^{7}$, anátema do século XIX, procurou compreender as relações sociais por meio de suas conexões, de suas redes. Afastado do ambiente acadêmico da época, seus escritos não almejam o cientificismo objetivista que ecoava alhures, distância que lhe permitiu traçar correlações entre indivíduo e sociedade por veios inauditos, onde a linguagem e a intersubjetividade forjam a base de sua sociologia, focada na expressão interativa entre indivíduo e sociedade. É aliás o reconhecimento do indivíduo como móvel das complexas relações que permite sua “pseudo-sociologia” ignorar qualquer diretriz normativa.

\section{O FLÂNEUR}

Baudelaire fez da figura do flâneur o protótipo do sujeito moderno. Tratava-se de um andamento muito particular, um apalpar na materialidade moderna, toda ela incrível. O próprio poeta descreve sua vagabundagem pelos bulevares de Paris como uma exploração das gamas perceptivas da cidade. Isso se fazia pelo vagar errante, gracioso e fortuito que mantém a percepção aberta para experiências de toda ordem. Perder-se nas malhas urbanas ou, como 
prefere Maffesoli, deixar-se levar pelas vagabundagens iniciáticas ${ }^{8}$, constitui o cerne da flânerie ${ }^{9}$. A natureza do flanador não deriva do arquétipo banal do burguês, mas da particular produção de sentido que a cidade possibilita ao cidadão: indivíduos que sentem a cidade.

O flâneur reinventa a cidade a cada passeio, interpreta a infra-estrutura amealhada de qualquer significação para aqueles que não compreendem suas peculiaridades, sua modernidade. O tecido urbano é grafado por um estriar singular, conjugando sua superfície e forjando um texto de significação privada. Seus estetas agem por apreensões individuais e nem mesmo suas remissões se dão coletivamente. A própria maneira de tecê-las: andar, apalpar, errar por caminhos não definidos define as categorias de apreensão pautadas por um ritmo próprio, que se preocupa tão somente com metáforas pessoais para a significação do espaço. Toma-se o espaço público como propriedade privada, e sentimentos de pertencimento são forjados por emulsões incoerentes que só se reúnem na unidade artificial do flâneur ${ }^{10}$.

Nos afamados ensaios de Walter Benjamin sobre o flâneur ${ }^{11}$, sobretudo em Paris do Segundo Império, o autor descreve esse andarilho da cidade com certa ironia, em nada muito disfarçada. Benjamin direcionava sua verve contra uma literatura muito em voga na Paris da segunda metade do século XIX, que tratava de descrever os habitantes da cidade de maneira amistosa, pueril, familiarizando os cidadãos com os tipos diferentes que perambulavam pelas ruas, uma tentativa de dirimir as inquietações e medos da metrópole. Essa literatura fisiologista objetivava ${ }^{12}$, diz Benjamin, dissolver o elemento estranho que a metrópole criava descontroladamente. O fundamental na descrição da flânerie, nos termos do ensaísta, não está nas tipificações de gêneros, na 'botânica do asfalto’, como a chamava. Benjamin se interessa por um desdobramento da narrativa baudelairiana, onde o conflito não é minimizado mas, pelo contrário, é o fio da estória. Não se procura apaziguar o conflito, mas tencionar, viver e conjugar a desordem.

A tensão dessa formação social, as contradições e ambigüidades que a cidade faz procriar podem ser encontradas na abordagem seminal de Baudelaire ${ }^{13}$, cuja proposição narrativa lembra mais um devaneio que qualquer descrição explicativa. Em Baudelaire concentra-se a ambigüidade imanente do flâneur, na medida em que a assincronia entre a multidão e indivíduo imprime recortes na cidade, atribuindo-se sentidos particulares ao espaço público, 
aqui entendido como "sem proprietário”. O gesto de flanar, aliás, constitui-se por si só em uma atitude de presença e ausência - simultaneamente - na aglomeração, pois insere o indivíduo na multidão ao mesmo tempo em que aprofunda sua solidão, seu isolamento da grande massa. É o turbilhão da cidade que, unindo todos os elementos, também aparta os sentidos de uns e de outros. Essa contradição permite ao flanador significar os espaços com um estilo não racionalista, quase um devaneio, tecendo uma subjetividade entre o passado e seus entrechoques.

\section{O BLASÉ}

Simmel, de maneira complementar, descreve a essência da urbanidade moderna como o blasé, a propriedade de não se deixar impressionar pelas diferenças abismais que a cidade proporciona: a base psicológica do tipo metropolitano de individualidade consiste na intensificação dos estímulos nervosos, que resulta na alternação brusca e ininterrupta entre estímulos exteriores e interiores ${ }^{14}$. Há, para Simmel, uma diferença fundamental entre o homem rural e o urbano no que respeita as condições psicológicas de cada um: a cidade imprime em seus habitantes grandes contrastes, traduzidos por imagens em mudança que convergem para uma única e mesma apreensão de impressões súbitas.

Essas condições materiais alteram os fundamentos sensoriais da vida psíquica. Atravessar a rua, comprar comida, pedir informação, requerem um ritmo e especificidade de ações em muito alienígenas para os habitantes da cidade pequena e do ambiente rural ${ }^{15}$. A metrópole fratura o rito constante da conquista de hábitos permanentes, típica da vida calma da cidade pequena. Para Simmel, a vida na metrópole exige de seus habitantes o uso exaustivo dos recursos cognitivos, pois a mudança constante no espaço vivido requer intelecção. Na medida em que o intelecto é entendido como a mais adaptável das forças interiores, Simmel compreende o indivíduo da metrópole como alguém que se pauta pela racionalidade, com a cabeça, ao invés do coração ${ }^{16}$, pois não haveria recurso mais indicado que o intelecto para lidar com as contingências metropolitanas ${ }^{17}$. 
Quando a reação aos fenômenos metropolitanos é transferida para essa região "mais dura”, o intelecto, o indivíduo se torna aparentemente frio, menos sensível às variações do ambiente e, em sua superfície, inacessível às regiões mais profundas da personalidade. A predominância da inteligência no homem metropolitano, diz Simmel, endurece-o. Paralelamente, a metrópole como sede da economia monetária concentra as relações econômicas de compra, venda e troca, onde tratar com homens é ineficiente e prosaico, trata-se com coisas. Todas as relações perpassam operações lógicas, e toda individualidade genuína é desprovida de consideração, pois não passível de mediação pecuniária. Para Simmel, a economia monetária e o domínio do intelecto são eventos intrinsecamente ligados, subproduto das aglomerações urbanas.

A diferença é fundamental: trata-se de transferir todas as relações emocionais e íntimas entre pessoas para princípios racionais. O homem vira um número e é tomado como um elemento em si mesmo indiferente: a individualidade é reduzida a quantidades, e apenas as realizações objetivas e mensuráveis são de interesse. São estes aspectos que contrastam com a natureza do pequeno círculo, em que essa vida psíquica (ou subjetividade) moderna é estranha e onde, de maneira inversa, o fato de se conhecer o distribuidor e o cliente são fatores fundamentais. A metrópole moderna, escreve Simmel, é provida quase que inteiramente para compradores inteiramente desconhecidos, que nunca entram pessoalmente no campo de visão propriamente dito do produtor ${ }^{18}$.

Os elementos que trouxeram exatidão e impessoalidade à vida ordinária também criaram uma individualidade singular que, para Simmel, é expresso pelo comportamento blasé ${ }^{19}$, fenômeno extremo da metrópole. A atitude blasé seria o resultado de uma carga excessiva de estímulos contrastantes, em rápida mudança e compressão exagerada, gerando uma espécie de indiferenciação no indivíduo aos fenômenos externos: tudo soa parecido, desprovido de novidade. A intelectualidade metropolitana seria resultado desse esgotamento nervoso, fruto da perseguição desregrada ao prazer que agita os nervos até o limite de reatividade, até que parem de reagir. De maneira oposta, mas complementar, é também por meio da rapidez e incoerência nas mudanças que as impressões menos ofensivas podem originar reações inesperadas, violentas, estirando os nervos bruscamente em outra direção até suas últimas reservas se exaurirem. O indivíduo blasé é, assim, alguém emocionalmente incapaz de reagir a novas sensações com a energia que se esperaria. Não há surpresa. 
A matriz fisiológica do blasé não se desvincula da economia monetária, da operação de reduzir tudo a números. O blasé, nesse sentido, consiste na deterioração do poder de discriminar e de valorar qualquer objeto de maneira particular. Claro que os objetos são percebidos, mas significados e valores são experimentados (ou vivenciados, nos termos de Benjamin) como destituídos de substância. Não apenas os objetos, mas também os indivíduos gravitam em prateleiras infinitas de um lusco-fusco uniformizado, onde nenhum elemento guarda preferência substantiva sobre outro, efeito reflexo da economia monetária, que assemelha indivíduos a objetos. Mas não se trata de um processo unidirecional: é a própria autopreservação subjetiva, reagindo à proliferação desmesurada de objetos, que desvaloriza o mundo objetivo. A personalidade embotada do indivíduo metropolitano é um mecanismo de defesa, uma recusa aos estímulos infinitos e uma procura por possibilidades de acomodação.

\section{O ZAPEADOR}

Apesar de haver tantas imagens do flâneur quanto concepções de modernidade, as imagens desse desfrute urbano espelham uma vida pública dada em termos individuais. São imagens que apresentam uma civilização dinamizada na esfera privada, nas relações profissionais e hábitos individuais. Do flanador ao blasé, e do blasé ao zapeador ${ }^{20}$, há uma linha contígua na individuação moderna, infelizmente de difícil apreensão. Isso porque quão maior a invisibilidade destes indivíduos, maiores são as possibilidades de leituras sociais ${ }^{21}$.

No celeiro contemporâneo de personagens e indivíduos, há pistas dessa individualidade hiperacelerada. Falamos em zapeador porque a metáfora televisiva do agente com um controle remoto parece mais exata. Também é possível se remeter ao ciberespaço, com suas variações de ciborgues, cibridos e quetais. Mas ciberespaço é uma metáfora espacial, um termo infeliz para designar uma dimensão de vivência desprovida de espaço. Há imaginários para se imergir, para zapear.

Zappeur porque o padrão interacional tem a lógica do controle-remoto, pilhando cenas, idéias e sons, e os organizando segundo um tempo interior que não se conecta com as aglomerações 
urbanas. O flâneur quer se perder na cidade, exercício impossível ao blasé, para quem todos os becos e vielas são idênticos em sua conformação metropolitana. Com o zappeur é também diferente. Os movimentos pela cidade são sincopados, combinando pacotes de subjetividade com figuras de seu imaginário. O nexo é, uma vez mais, inteiramente dado na esfera privada.

Zapeamos diariamente inúmeros pacotes de subjetividade prontos para consumo. Consumo não como efeito mecânico da relação pecuniária, mas elemento interagente na eclosão de processos, sismógrafo da movimentação cultural. As figuras contemporâneas embaralham os ícones mais virgens, misturando sinais antagônicos e fazendo da identidade um produto do consumo, este em constante reciclagem nômade. Zapear é ser espectador desse mundo de imagens sobrepostas.

Também o corpo projeta ícones de identificação, com adereços que não enfeitam, mas servem ao propósito de comunicar quem se é, de onde se veio e para onde se está indo. Tatuagens, body piercings, roupa démodé ou unissex, visual vintage. Adotam-se padrões de vida como padrões de consumo, numa curiosa confusão entre ser e aparentar. À austeridade moderna, emerge a opção estética nem sempre vinculada à conduta ética: vestidos com as anti-regras de um despojamento obrigatório. Os layouts são muitos: careca, cabelo ensebado com gel, topete, tênis, calça jeans, celular, mochila up to date, barba por fazer, costeleta sempre feita o estilo é étnico, conforme a world music, a moda é street, conforme a passarela, e a ideologia é a das minorias, porquanto mediadas. Se a identidade é uma proposição inoperante, também o são os mecanismos de identificação.

Quem são os zapeadores? Basta olhar mais de perto: são publicitários, jornalistas, arquitetos, fotógrafos, designers. Indivíduos que trabalham com imagens em um mundo de demanda infinita do material. Dietmar Kamper conta que uma enquete surpresa constatou que a profissão que as jovens alemãs mais desejam é a de modelo, e entre os jovens, a de artista, isto é, designer: uma acomodação super-rápida às exigências sociais: uns desejam tornar-se imagem, outros querem fazer imagens, ambos para capturar a única significação que ainda conta: atenção pública ${ }^{22}$.

E onde estão estes indivíduos? Eles habitam a música, que é eletrônica, do trance ao rap, nos 
conformes com a era tecnológica. Festivais turbinados por anfetaminas superprocessadas. O ambiente é lounge, o sentimento, amor, e a ordem, transcendente. A conversa é simbólica e não-gramatical, e a poesia, visual. São estas experiências compartilhadas que legitimam os sujeitos em condição de criadores de linguagem - desde as gírias e neologismos até a produção de novas narrativas que forneçam sentidos para experiências que a cultura ainda não classificou $^{23}$. Indivíduos e objetos gravitam ao redor do consumo, onde shoppings e clubs não são espaços pra comprar e dançar, mas locais para ver, para se ver e para ser visto.

A referência cultural opõe-se à política institucional ou a qualquer imperativo ideológico. Em um sentido inteiramente antagônico, a referência máxima é a tecnologia, em um não usual arcabouço de citações e fragmentos de comerciais, de produtos e gadgets diversos. Cultura de mídias, agenciada por elementos desconexos ${ }^{24}$. Subjetividades são codificadas por objetos tecnológicos, eles todos sem referência concreta a um lugar ou conjunto de crenças. A liberdade se quer total, e por isso mesmo, ineficaz. Quando se viu, o sujeito era uma lenda, e a lenda desapareceu. Só há indivíduos, muitos e diferentes. Fluem nessa nervura social e a tentativa de enquadrá-los dentro de uma totalidade coesa é vã.

\section{BIBLIOGRAFIA}

BAUDELAIRE, Charles, O spleen de Paris, pequenos poemas em prosa. Rio de Janeiro: Imago, 1995.

BAUMAN, Zygmunt. Modernidade Líquida. Rio de Janeiro: Jorge Zahar, 2001.

Mais!, Domingo, 19/10/2003.

A Sociedade Líquida. Entrevista cedida ao Jornal Folha de São Paulo, Caderno

BENJAMIN, Walter. Obras Escolhidas III. São Paulo, Brasiliense, 1994.

BORGES, Julio Daio. Retrato do jovem quando artista no século XXI. Digestivo Cultural. Disponível em: http://www.digestivocultural.com/colunistas/coluna.asp?codigo=665

GLUCK, Mary. The Flâneur and the Aesthetic Appropriation of Urban Culture in Mid-19 ${ }^{\text {th }}$-century Paris. Theory, Culture \& Society. Explorations in Critical Social Science. vol ${ }^{\circ}$ 20, n 5, 2003.

LEMOS, André. Ciber-Flânerie. IN: FRAGOSO, Suely \& DA SILVA, Dinorá Fraga. Comunicação na cibercultura. São Leopoldo: Unisinos, 2001.

KAMPER, Dietmar. Imanência dos media e corporeidade transcendental. Oito postos de observação para um futuro medial. Tradução de Ciro Marcondes filho. São Paulo, 1998.

KEHL, Maria Rita (org). Função Fraterna. Rio de Janeiro: Relume Dumará, 2000. 
PEREIRA, Beltrina da Corte, São Paulo: Cidade misturada/cidade inconclusa: zapeando a metrópole metalizada. Tese de Doutorado, ECA-USP, 1997.

PEREIRA, Wellington. Diário de um Zappeur: Elogio de uma estética do Individualismo. InSite Universitário. Disponível em http://www.insite.pro.br/Artigo\%20Wellington\%20Di\%C3\%A1rio.htm

SIMMEL, Georg. A metrópole e a vida mental. IN: Velho, Otavio (org). O Fenômeno Urbano. Rio de Janeiro: Jorge Zahar, 1967.

TARDE, Gabriel. Monadologia e sociologia. Rio de Janeiro: Vozes, 2003.

A opinião e as massas. São Paulo: Martins Fontes, 1992.

\section{NOTAS}

${ }^{1}$ Marco Toledo de Assis Bastos é Doutorando e Mestre em Ciências da Comunicação pela Universidade de São Paulo. É pesquisador do FiloCom (Núcleo de Estudos Filosóficos da Comunicação), onde trabalha a lógica do sentido na cibercultura. Contato: herrcafe@uol.com.br

${ }^{2}$ Bauman, Zygmunt. Modernidade Líquida. Rio de Janeiro: Jorge Zahar, 2001. (p.85).

${ }^{3}$ Idem, (p.29).

${ }^{4}$ Bauman, Zygmunt. A Sociedade Líquida. Entrevista cedida ao Jornal Folha de São Paulo, Caderno Mais!, Domingo, 19/10/2003, (p.6).

${ }^{5}$ Simmel, Georg. A metrópole e a vida mental. IN: Velho, Otavio (org). O Fenômeno Urbano. Rio de Janeiro: Jorge Zahar, 1967. (p.14). A questão sobre a importância de trabalhar a dimensão individual e as micro-manifestações da sociedade perfaz toda a obra de Simmel, antes mesmo da virada do século XX. Aparece bem resumida neste trecho: "A escala dos valores humanos já não é constituída pelo 'ser humano geral' em cada indivíduo, mas antes pela unicidade e insubstitubilidade qualitativas do homem. A história externa e interna de nosso tempo segue seu curso no interior da luta e nos entrelaçamentos em mudança dessas duas maneiras de definir o papel do indivíduo no todo da sociedade. É função da metrópole fornecer a arena para este combate e a reconciliação dos combatentes.” Idem, (p.27).

6 "Cada formação social promove seu próprio tipo de racionalidade, investe seu próprio significado na idéia de uma estratégia racional de vida" Bauman, Zygmunt. Modernidade Líquida. Rio de Janeiro: Jorge Zahar, 2001. (p.125).

7 Jean Gabriel Tarde, contemporâneo de Émile Durkheim, foi como Simmel deliberadamente descartado por seus pares. As razões, políticas, são facilmente compreendidas em razão do reacionarismo, misticismo e religiosidade que marcam seus escritos. No entanto, Tarde acertou em cheio ao procurar entender a sociedade não como um construto de partes antagônicas, dispostas claramente, mas como forças tencionadas, contraditórias e que se alimentam mutuamente. Grosso modo, é um pensamento que não foi inteiramente contaminado pelo positivismo da época, nem pelo estruturalismo, utilitarismo ou materialismo dialético que viriam em seguida. A esse respeito, ver: Tarde, Gabriel. Monadologia e sociologia. Rio de Janeiro: Vozes, 2003. E também: Tarde, Gabriel. A opinião e as massas. São Paulo: Martins Fontes, 1992.

${ }^{8}$ André Lemos faz uso da mesma terminologia para trabalhar o tema. Ver: Lemos, André. CiberFlânerie. IN: Fragoso, Suely \& Da Silva, Dinorá Fraga. Comunicação na cibercultura. São Leopoldo: Unisinos, 2001. (p.45-46).

${ }^{9}$ Termo que designa, e não por menos, algo ou alguém inoperante; pessoa que não trabalha; sem valor; preguiçosa; algo ocioso, sem propósito e que fica "à toa"; desempregado ou aquele que "mata o 
tempo”; desocupado. A oitava edição do dicionário da Academia Francesa (de 1932-35, quando a primeira edição data de 1694), entrementes, já incorporava as definições de 'flânerie' como 'ato de passear' e 'flâneur' como 'aquilo ou aquele que passeia' e ainda 'flânocher, aquele ou aquilo que passeia calmamente'.

10 "Não é dado a qualquer um mergulhar na multidão: tal desfrute é uma arte, e só faz, às expensas do gênero humano, esse lauto banquete de vitalidade quem, desde o berço, recebeu de uma fada o gosto do disfarce e da máscara, o ódio do domicílio e a paixão da viagem”. Baudelaire, Charles, O spleen de Paris, pequenos poemas em prosa. Rio de Janeiro: Imago, 1995. (p.57).

${ }^{11}$ Benjamin, Walter. Obras Escolhidas III. São Paulo, Brasiliense, 1994.

${ }^{12}$ Walter Benjamin chamava a literatura fisiologista de 'material para ser vendido em feiras', produto essencialmente pobre e invariavelmente 'pequeno-burguês'.

${ }^{13}$ Para tanto, ver: Baudelaire, Charles, O spleen de Paris, pequenos poemas em prosa. Rio de Janeiro: Imago, 1995.

${ }^{14}$ Simmel, Georg. A metrópole e a vida mental. IN: Velho, Otavio (org). O Fenômeno Urbano. Rio de Janeiro: Jorge Zahar, 1967. (p.14).

15 "A metrópole extrai do homem, enquanto criatura que procede a discriminações, uma quantidade de consciência diferente da que a vida rural extrai. Nesta, o ritmo da vida e do conjunto sensorial de imagens flui mais lentamente, de modo mais habitual e mais uniforme. É precisamente nesta conexão que o caráter sofisticado da vida psíquica metropolitana se torna compreensível - enquanto oposição à vida de pequena cidade, que descansa mais sobre relacionamentos profundamente sentidos e emocionais”. Idem.

${ }^{16}$ Ibidem, (p.15).

${ }^{17}$ Não se trata de uma suposta formação inata ao habitante da grande cidade, pois o próprio Simmel indica que as mentes mais conservadoras, à força dos transtornos que tal modo de vida impõe, acabam por se acomodar ao ritmo dos acontecimentos. Nas variadas situações que a cidade grande produz, o que ocorre é o uso do intelecto - e não do coração, dos sentimentos - para se lidar com os discretos fenômenos da cidade. Trata-se de uma operação onde a racionalidade assume qualquer prerrogativa psíquica, e cujo objetivo é defender o indivíduo das correntes externas que ameaçam seu ambiente e que, de outra maneira, o desenraizariam ininterruptamente.

${ }^{18}$ Ibidem, (p.16).

${ }^{19}$ Simmel entende o blasé de forma positivada, como característica "que as pessoas estúpidas não tem”. Ibidem, (p.18).

${ }^{20}$ Sobre o zapeador, ver Pereira, Beltrina da Corte, São Paulo: Cidade misturada/cidade inconclusa: zapeando a metrópole metalizada. Tese de Doutorado, ECA-USP, 1997 e Pereira, Wellington. Diário de um Zappeur: Elogio de uma estética do Individualismo. InSite Universitário. Disponível em http://www.insite.pro.br/Artigo\%20Wellington\%20Di\%C3\%A1rio.htm

${ }^{21}$ Sobre a leitura da cidade por um agente invisível, ver Gluck, Mary. The Flâneur and the Aesthetic Appropriation of Urban Culture in Mid-1 $9^{\text {th }}$-century Paris. Theory, Culture \& Society. Explorations in Critical Social Science. vol ${ }^{\circ}$ 20, $n^{\circ}$ 5, 2003.

${ }^{22}$ Kamper, Dietmar. Imanência dos media e corporeidade transcendental. Oito postos de observação para um futuro medial. Trad. Ciro Marcondes filho. São Paulo, 1998.

${ }^{23}$ Kehl, Maria Rita (org). Função Fraterna. Rio de Janeiro: Relume Dumará, 2000.

24 "Como referência máxima, a indústria. O estudo das marcas se estabelecerá como uma forma de eruditismo. Os comerciais (ou 'filmes'), como um instrumento na decodificação do mundo. Terá no século XX o seu marco zero. Falará em termos de décadas e não de séculos. Da psicanálise dissolvida em psicologia restarão tão somente os arquétipos; adotá-los-á, como guias. Emprestará glamour a produtos de baixa extração, convertendo em fashion até as havaianas mais legítimas. Desconfiará da medicina tradicional, preferindo sempre a alternativa. Procurará viver coisas verdadeiras, e não essa falsa rotina. Como supremo objetivo, aprender mais e mais sobre o mundo; aprender a aprender. $\mathrm{O}$ melhor trabalho ainda está por vir; e a melhor viagem, também. Não fará coleção de coisa alguma, agarrar-se-á com unhas e dentes à transitoriedade do dia-a-dia. Conceito é tudo, e a forma vem sempre 
antes do conteúdo. Sem optar por religião alguma, nutrirá uma admiração perene por figuras como Buda e Jesus Cristo; ícones para adornar o altar de uma vida vazia. Considerar-se-á uma pessoa única”. Borges, Julio Daio. Retrato do jovem quando artista no século XXI. Digestivo Cultural. Disponível em: http://www.digestivocultural.com/ colunistas/coluna.asp?codigo=665 